\title{
XPS and GDOES Characterization of Porous Coating Enriched with Copper and Calcium Obtained on Tantalum via Plasma Electrolytic Oxidation
}

\author{
Krzysztof Rokosz, ${ }^{1}$ Tadeusz Hryniewicz, ${ }^{1}$ Patrick Chapon, ${ }^{2}$ \\ Steinar Raaen, ${ }^{3}$ and Hugo Ricardo Zschommler Sandim ${ }^{4}$ \\ ${ }^{1}$ Division of Bioengineering and Surface Electrochemistry, Department of Engineering and Informatics Systems, \\ Faculty of Mechanical Engineering, Koszalin University of Technology, Racławicka 15-17, 75-620 Koszalin, Poland \\ ${ }^{2}$ HORIBA Jobin Yvon S.A.S., 16-18 rue du Canal, 91165 Longjumeau Cedex, France \\ ${ }^{3}$ Department of Physics, Norwegian University of Science and Technology (NTNU), Realfagbygget E3-124 Høgskoleringen 5, \\ 7491 Trondheim, Norway \\ ${ }^{4}$ Department of Materials Engineering, Lorena School of Engineering, University of Sao Paulo, 12602-810 Lorena, SP, Brazil \\ Correspondence should be addressed to Tadeusz Hryniewicz; tadeusz.hryniewicz@tu.koszalin.pl
}

Received 29 August 2016; Revised 10 November 2016; Accepted 27 November 2016

Academic Editor: Michele Fedel

Copyright (C) 2016 Krzysztof Rokosz et al. This is an open access article distributed under the Creative Commons Attribution License, which permits unrestricted use, distribution, and reproduction in any medium, provided the original work is properly cited.

XPS and GDOES characterizations of porous coatings on tantalum after Plasma Electrolytic Oxidation (PEO) at $450 \mathrm{~V}$ for 3 minutes in electrolyte containing concentrated (85\%) phosphoric acid with calcium nitrate and copper (II) nitrate are described. Based on the obtained data, it may be concluded that the PEO coating consists of tantalum $\left(\mathrm{Ta}^{5+}\right)$, calcium $\left(\mathrm{Ca}^{2+}\right)$, copper $\left(\mathrm{Cu}^{2+}\right.$ and $\left.\mathrm{Cu}^{+}\right)$, and phosphates $\left(\mathrm{PO}_{4}{ }^{3-}\right)$. It has to be pointed out that copper and calcium are distributed throughout the volume. The authors also propose a new model of PEO, based on the derivative of GDOES signals with sputtering time.

\section{Introduction}

Tantalum, which was discovered by the Swedish chemist and mineralogist Anders Gustaf Ekeberg in 1802, is a transition metal of grayish-silver color with atomic number and atomic mass equal to 73 and 180.9479 , respectively. It is very hard, malleable, and ductile and has excellent corrosion resistance to acids and other strong chemicals. Therefore it is used inter alia in chemical, metallurgy, textile, aerospace, medical, dental, electronic, and optic industries. In case of biomedical applications it is used for surgical clips, bone grafts, and plates for cranioplasty as well as mesh for abdominal wall reconstruction and dental implants [1]. Tantalum [2-5] as well as niobium [6-9], zirconium [10-13], and titanium [1417] and its alloys [18-24] may be treated by Plasma Electrolytic Oxidation method, known also worldwide as Micro Arc Oxidation to form porous coating containing chemical compounds dissolved in a solution. The results presented in paper are the first ones and in our opinion interesting for other researchers; in near future we will present the new ones, which will be obtained in electrolytes based on different concentrations of $\mathrm{Cu}\left(\mathrm{NO}_{3}\right)_{2}$ and $\mathrm{Ca}\left(\mathrm{NO}_{3}\right)_{2}$ in $\mathrm{H}_{3} \mathrm{PO}_{4}$. In addition, it is beneficial to also enrich the porous coatings with antibacterial agent such as copper [25-32] to speed up wound healing and reduce the risk of infection after surgery.

In the present paper, authors described the porous coating obtained on Ta surface and featuring copper and calcium enrichment in its volume. XPS and GDOES techniques allowed characterizing the in-depth composition and description of the chemical compounds of the obtained PEO coating.

\section{Method}

2.1. Material. A set of tantalum samples with Plasma Electrolytic Oxidation (Micro Arc Oxidation) served for the 
study. The samples (from same original material) were cut in the shape of cylindrical specimens of diameter $10 \mathrm{~mm}$ with a height of $5 \mathrm{~mm}$. The round top surface of the samples was mechanically polished using $\mathrm{SiC}$ abrasive paper with grain of 1000-grit size.

2.2. Set-Up and Parameters. The Plasma Electrolytic Oxidation (PEO) was performed at the DC voltage of $450 \pm 10 \mathrm{~V}$ during 3 minutes of treatment. The studies were carried out with an electrolyte of initial temperature of $20 \pm 2^{\circ} \mathrm{C}$. For these studies, the electrolyte was composed of $300 \mathrm{~g} \mathrm{Cu}\left(\mathrm{NO}_{3}\right)_{2}$ and $300 \mathrm{~g} \mathrm{Ca}\left(\mathrm{NO}_{3}\right)_{2}$ in 1 liter of concentrated orthophosphoric acid $\left(85 \% \mathrm{H}_{3} \mathrm{PO}_{4}\right)$. For each run, an electrolytic cell made of glass was used, containing up to $500 \mathrm{ml}$ of the electrolyte. At the beginning the one liter of orthophosphoric acid was warmed up to about $70^{\circ} \mathrm{C}$ and the two salts were added. After that the salts were mixed for the time of 6 hours. In that case the colloid, not a solution, was obtained. It has to be also pointed out that just after preparing the electrolyte was used.

2.3. SEM and XPS Studies. The scanning electron microscope Quanta 250 FEI with Low Vacuum and ESEM mode and a field emission cathode to obtaining images of top surface of tantalum after Plasma Electrolytic Oxidation was used. The $\mathrm{X}$-ray Photoelectron Spectroscopy (XPS) measurements on tantalum samples were performed on a SCIENCE SES 2002 instrument using a monochromatic (Gammadata-Scienta) $\mathrm{Al}$ $\mathrm{K}(\mathrm{alpha})(h v=1486.6 \mathrm{eV}) \mathrm{X}$-ray source $(18.7 \mathrm{~mA}, 13.02 \mathrm{kV})$. Scans analyses were carried out with an analysis area of $1 \times$ $3 \mathrm{~mm}$ and a pass energy of $500 \mathrm{eV}$ with the energy step $0.2 \mathrm{eV}$ and step time $200 \mathrm{~ms}$. The binding energy of the spectrometer has been calibrated by the position of the Fermi level on a clean metallic sample. The power supplies were stable and of high accuracy. The experiments were carried out in an ultrahigh-vacuum system with a base pressure of about $6 \cdot 10^{-8} \mathrm{~Pa}$. The power of the $\mathrm{X}$-ray source was given as follows: $18.7 \mathrm{~mA} \times$ $13.02 \mathrm{kV}=243.5 \mathrm{~W}$. The pass energy of $500 \mathrm{eV}$ gives an energy resolution of near $1 \mathrm{eV}$. This high pass energy was chosen to improve the signal to noise ratio in the photoemission spectra. The XPS spectra were recorded in normal emission. For the XPS analyses the CasaXPS 2.3.14 software (Shirley background type) [33] with the help of XPS tables [28] was used. All the binding energy values presented in that paper were charge corrected to C $1 \mathrm{~s}$ at $284.8 \mathrm{eV}$. The number of sweeps during the XPS measurements was different for each element, because of different noisiness and amplitude of those signals. Hence, because of strong signals for carbon (C 1s), oxygen $(\mathrm{O} 1 \mathrm{~s})$, and calcium, only 9 sweeps ( signal/noise $=3$ ) were performed. In case of $\mathrm{P}$ and $\mathrm{Ta}$, for phosphorus (P 2p) and tantalum (Ta 4f, Ta 4d), 16 (signal/noise = 4) and 64 sweeps (signal/noise $=8$ ), respectively, were used. For very weak signals of copper ( $\mathrm{Cu} 2 \mathrm{p}, \mathrm{Cu}$ LMM), 225 sweeps were done giving a signal to noise ratio $(\mathrm{S} / \mathrm{N})$ equaling 15 . In case of the two XPS survey spectra, only 1 sweep for each one was performed.

2.4. GDOES Studies. The Glow Discharge Optical Emission Spectroscopy (GDOES) measurements on PEO oxidized tantalum samples were performed on a Horiba Scientific

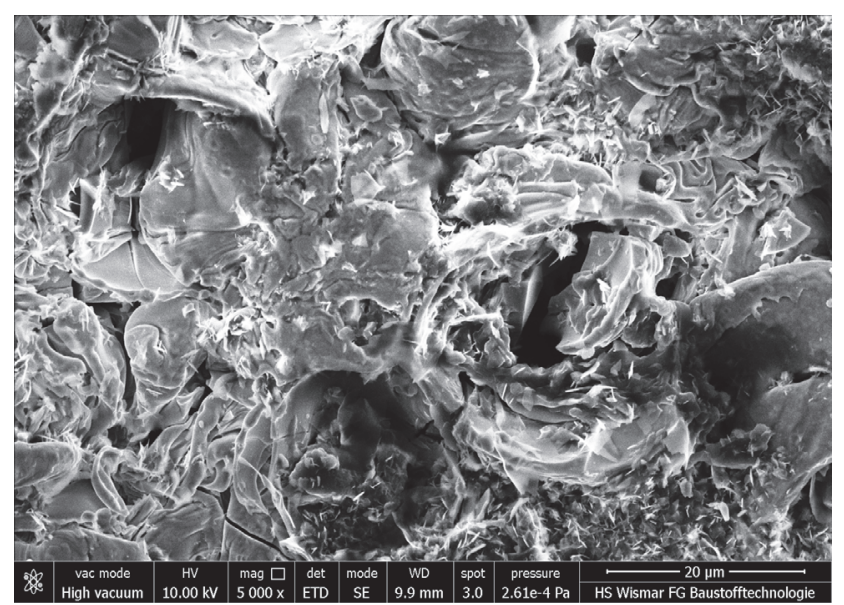

FIgURE 1: SEM image of tantalum surface after PEO treatment at $450 \mathrm{~V}$ in electrolyte containing $\mathrm{Ca}\left(\mathrm{NO}_{3}\right)_{2}$ and $\mathrm{Cu}\left(\mathrm{NO}_{3}\right)_{2}$.

GD Profiler 2 instrument using radio frequency (RF) asynchronous pulse generator with the following conditions: pressure: $700 \mathrm{~Pa}$, power: $40 \mathrm{~W}$, frequency: $3000 \mathrm{~Hz}$, duty cycle: 0.25 , and anode diameter: $4 \mathrm{~mm}$. The signals of copper $(325 \mathrm{~nm})$, phosphorus $(178 \mathrm{~nm})$, oxygen $(130 \mathrm{~nm})$, nitrogen $(149 \mathrm{~nm})$, hydrogen $(122 \mathrm{~nm})$, and tantalum $(301 \mathrm{~nm})$ were measured [34].

\section{Results and Discussion}

In Figure 1, the SEM image is presented. The observed surface of tantalum after plasma electrolytic treatment is not so porous as it was observed on titanium and its alloys. However, the obtained PEO coating is not as flat as after electrochemical polishing and may be used in production of promoters for catalysts or as biomaterial.

In Figures 2 and 3, survey and XPS spectra, respectively, are shown. It has to be noted that, to understand the chemical composition of the top layer (top $10 \mathrm{~nm}$ ) of PEO coating, the XPS measurements are necessary. Based on the information from Figure 2 spectra one may note that oxygen $(\mathrm{O} 1 \mathrm{~s}, \mathrm{O}$ $\mathrm{KLL}$ ), carbon (C 1s), phosphorus (P 2s, P 2p), calcium (Ca 2p, Ca 3p, Ca 3s), copper ( $\mathrm{Cu} 2 \mathrm{p}$ ), and tantalum ( $\mathrm{Ta} 4 \mathrm{f}, \mathrm{Ta} 4 \mathrm{~d}, \mathrm{Ta}$ $5 \mathrm{~s}$, Ta $5 \mathrm{p})$ were found out. Because the copper $(\mathrm{Cu} 2 \mathrm{p})$ signal was very weak, the Auger copper peak $\left(\mathrm{Cu} \mathrm{L}_{3} \mathrm{M}_{4,5} \mathrm{M}_{4,5}\right)$ was not visible after 1 sweep survey scan.

In order to find the oxidation states of all elements and to calculate the chemical composition of the top $10 \mathrm{~nm}$ of the PEO coating, it was necessary to perform XPS high-resolution studies. The results of those high-resolution XPS measurements are demonstrated in Figure 3. Carbon, which most probably originates from the purification process $\left(\mathrm{C}_{2} \mathrm{H}_{5} \mathrm{OH}\right)$ and the atmosphere $\left(\mathrm{CO}_{2}\right)$, should be treated as a contamination. However, it is necessary for the calibration process of all spectra (the signal of $\mathrm{C}-\mathrm{C} / \mathrm{C}-\mathrm{H}$ bonding must be set at $284.8 \mathrm{eV}$ ) and because of interpretation process, with the use of data from reference XPS bases. On the basis of information from Figure 3, it can be stated that the top $10 \mathrm{~nm}$ of PEO coating consists of phosphates of tantalum and/or 


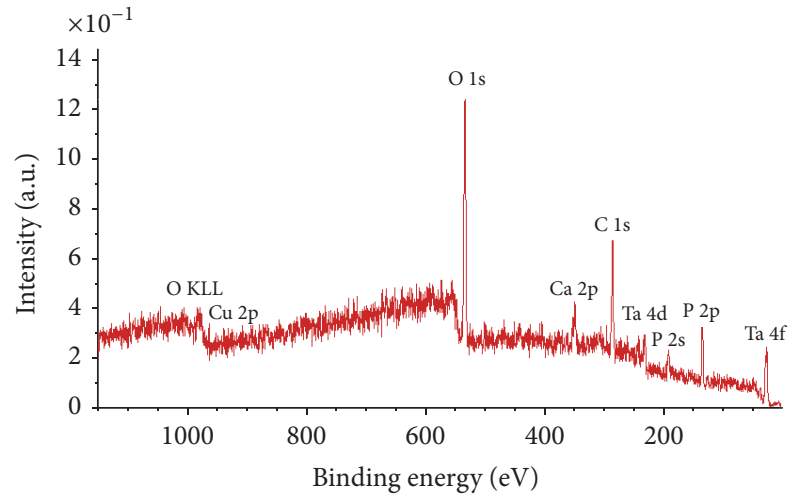

(a)

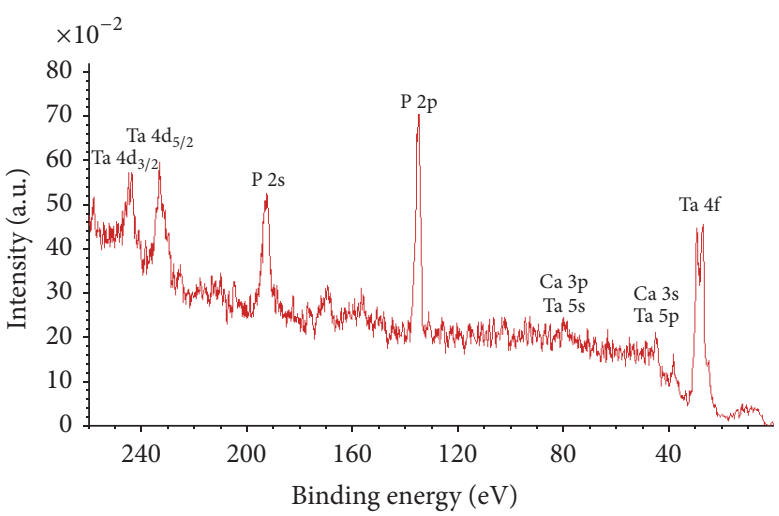

(b)

FIGURE 2: XPS survey spectra of top $10 \mathrm{~nm}$ of tantalum surface after PEO treatment at $450 \mathrm{~V}$ in electrolyte containing $\mathrm{Ca}\left(\mathrm{NO}_{3}\right)_{2}$ and Cu(NO$)_{2}$, with maximum binding energy $1150 \mathrm{eV}$ (a) and $260 \mathrm{eV}$ (b).
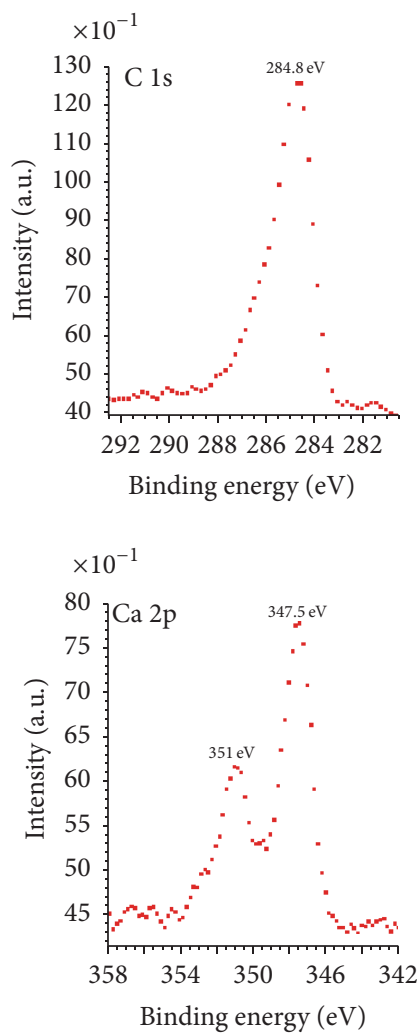
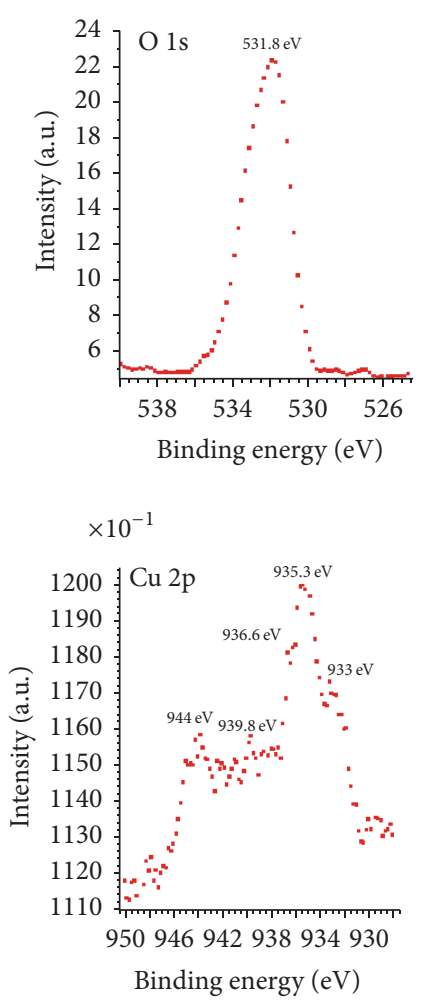
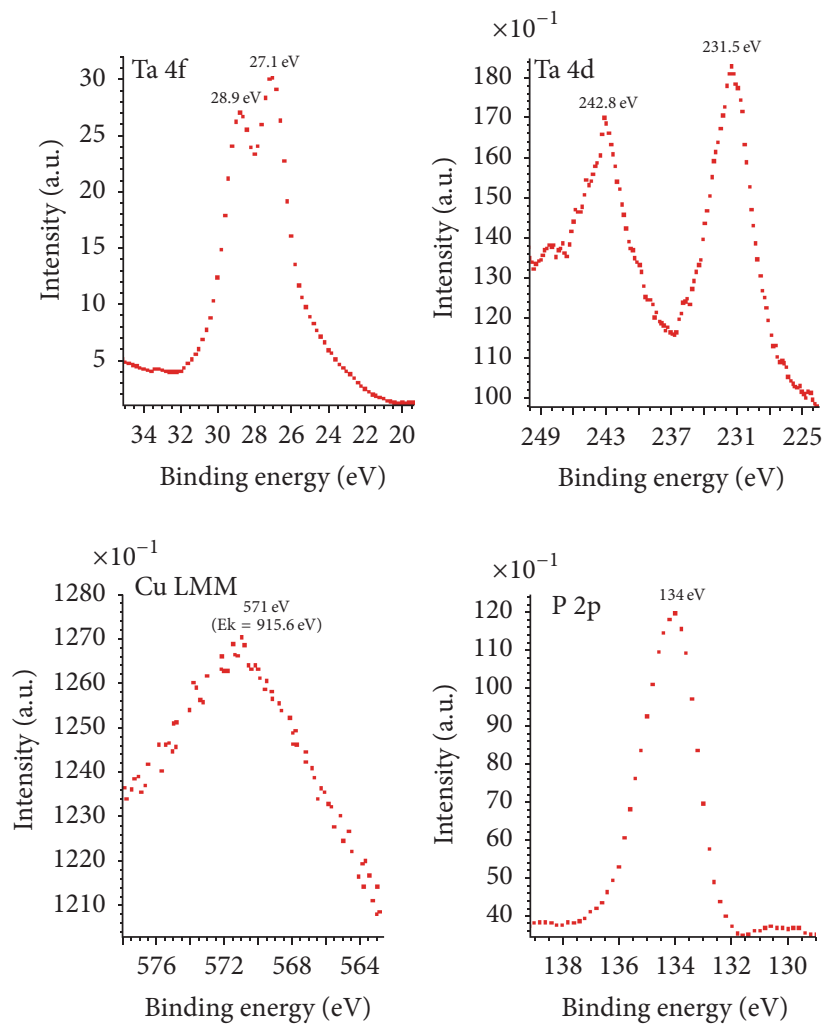

Figure 3: XPS spectra of carbon (C 1s), oxygen (O 1s), tantalum (Ta 4f, Ta 3d), calcium (Ca 2p), copper (Cu 2p, Cu LMM), and phosphorus (P 2p).

calcium and copper, the binding energy for phosphorus ( $\mathrm{P}$ $2 \mathrm{p})$ is $134 \mathrm{eV}$, and that of oxygen (O 1s) is $513.8 \mathrm{eV}$. The binding energy of calcium ( $\mathrm{Ca} 2 \mathrm{p}$ ), which equals $347.5 \mathrm{eV}$, suggests that calcium is on the second stage of oxidation $\left(\mathrm{Ca}^{2+}\right)$ and occurs most likely as $\mathrm{CaHPO}_{4}$ and/or $\mathrm{Ca}_{3}\left(\mathrm{PO}_{4}\right)_{2}[27,28]$. In order to find the oxidation stages of copper as well as differentiate $\mathrm{Cu}^{0}$ from $\mathrm{Cu}^{+}$and $\mathrm{Cu}^{2+}$, the regions of the spectra, that is, $\mathrm{Cu} 2 \mathrm{p}$ and $\mathrm{Cu} \mathrm{L}_{3} \mathrm{M}_{4,5} \mathrm{M}_{4,5}$ [29-33], have to be studied. Based on binding energies of $\mathrm{Cu} 2 \mathrm{p}$ spectra and their modified Auger parameters (MAP), which are equal to $935.3 \mathrm{eV}(\mathrm{MAP}=1850.9 \mathrm{eV})$ and $936.6 \mathrm{eV}(\mathrm{MAP}=1851.6 \mathrm{eV})$, and their satellites with binding energies equaling $939.8 \mathrm{eV}$ and $944 \mathrm{eV}$, it is possible to state surely that copper is on the second stage of oxidation $\left(\mathrm{Cu}^{2+}\right)$. However, the $\mathrm{Cu} 2 \mathrm{p}$ binding energy equaling $933 \mathrm{eV}$ with the modified Auger parameter amounting to $1848.6 \mathrm{eV}$ corresponds to $\mathrm{Cu}^{+}$.

The spectrum of $\mathrm{Ta} 4 \mathrm{f}$ binding energy region may be deconvoluted into two peaks, which are centered at $27.1 \mathrm{eV}$ (Ta 
TABLE 1: Total chemical composition of coating formed after PEO treatment at $450 \mathrm{~V}$ on tantalum with outer carbon- and biocontaminations sublayer at $\%$ (based on XPS results).

\begin{tabular}{lccccc}
\hline Tantalum & Calcium & Copper & Phosphorus & Oxygen & Carbon \\
\hline 1.1 & 4.6 & 0.3 & 17.7 & 37.7 & 38.6 \\
\hline
\end{tabular}

TABLE 2: Total chemical composition of coating formed after PEO treatment at $450 \mathrm{~V}$ on tantalum without outer carbon- and biocontaminations sublayer at\% (based on XPS results).

\begin{tabular}{lccc}
\hline Tantalum & Calcium & Copper & Phosphorus \\
\hline 4.8 & 19.4 & 1.3 & 74.5 \\
\hline
\end{tabular}

$\left.4 \mathrm{f}_{7 / 2}\right)$ and $28.9 \mathrm{eV}\left(\mathrm{Ta} 4 \mathrm{f}_{5 / 2}\right)$, which may suggest that tantalum is on the fifth stage of oxidation $\left(\mathrm{Ta}^{5+}\right)$.

Based on this information, from XPS data, complex formulae should contain tantalum, calcium, and copper phosphates which may be representative for the studied PEO coating.

In Tables 1 and 2, the chemical compositions of PEO layer are presented, wherein in the first one are presented results containing outer carbon- and biocontaminations sublayer. Table 2 contains calculated values without oxygen ( $\mathrm{O} 1 \mathrm{~s})$ and carbon (C 1s). Based on these data, it is possible to conclude that the top $10 \mathrm{~nm}$ layer of PEO coating consists mainly of calcium phosphates with some tantalum and/or copper phosphates. It is a very good result because the human bone is containing mainly hydroxyapatite, which consists generally of $\mathrm{Ca}^{2+}$ and $\mathrm{PO}_{4}{ }^{3-}$. The additional doping with copper provides additional antibacterial properties for the coating that is necessary because of high amount of microbes in live organism during surgery. It has to be pointed out that $\mathrm{Cu}^{2+}$ ions, normally located within hydroxyapatite- (HA-) structure $\left[\mathrm{Ca}_{5}\left(\mathrm{PO}_{4}\right)_{3}(\mathrm{OH})\right.$ or $\left.\mathrm{Ca}_{10}\left(\mathrm{PO}_{4}\right)_{6}(\mathrm{OH})_{2}\right]$, are randomly substituted (or superimposed) by $\mathrm{Cu}^{2+}$ [35] coming from the electrolyte.

In Figure 4, the GDOES depth profile results of tantalum, phosphorus, oxygen, copper, calcium, hydrogen, and nitrogen on one graph, are shown. Important is to remember that the curves presented in Figure 3 are not in atomic nor weight percentage but only show the relative light intensities of GDOES signals multiplied by $10,1.5,1,1.5,1.5,1.13$, and 7 for hydrogen, nitrogen, oxygen, calcium, phosphorus, tantalum, and copper, respectively (qualitative depth profiles). By the same token the $x$-axis displays the erosion time and not directly the depth (as it is difficult to precisely estimate rough, porous materials).

The signals were scaled on the model describing the coating obtained on tantalum by PEO. From these GDOES signals, it is possible to find out three sublayers. The firsttop one ( $0-40$ s by sputtering time) is containing the smallest amount of tantalum and calcium and the highest amount of phosphorus, copper, oxygen, nitrogen, and hydrogen. The second one ( $40-80 \mathrm{~s}$ by sputtering time) is semiporous and enriched in calcium, copper, and oxygen. The next sublayer, transition one ( $80-300 \mathrm{~s}$ by sputtering time), has local maxima of phosphorus and hydrogen, which maybe

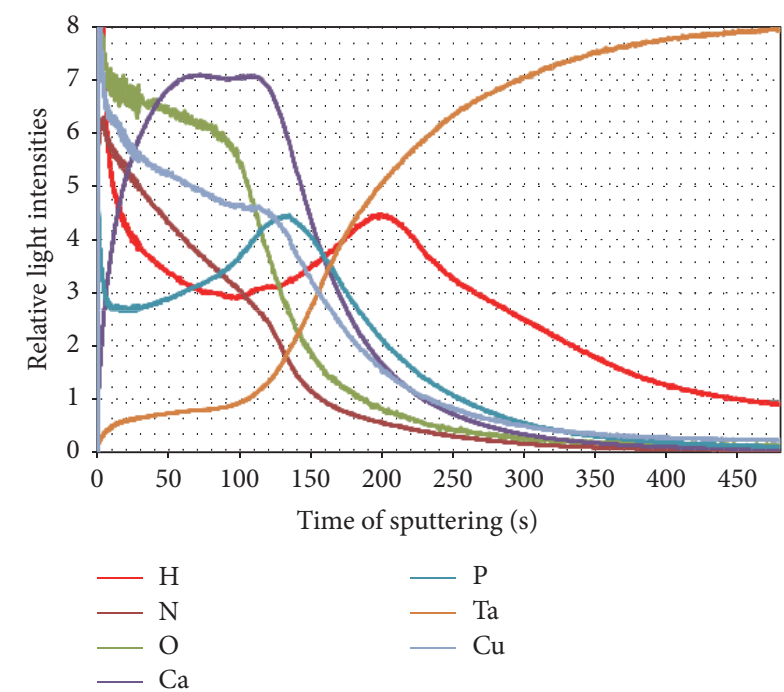

FIGURE 4: Relative light intensities of tantalum, phosphorus, calcium, copper, oxygen, and nitrogen of PEO coating formed on tantalum obtained by GDOES method. The first $20 \mathrm{~s}$ was recorded with higher acquisition frequency and no smoothing with equal spacing was applied; this is why the further derivatives look more noisy in this first part.

reveal the presence of molecules of water or phosphoric acid inside that sublayer.

To find out all the sublayers, based on Figure 4, the derivatives by sputtering time of the GDOES signals were calculated and are presented in Figure 5, for phosphorus, copper, oxygen, nitrogen, tantalum, and calcium along with their derivatives, respectively. Based on that mathematical analysis of these signals, it was possible to find the three sublayers: the first-top one (from 0 till about $40 \mathrm{~s}$ ), the second one (from about $40 \mathrm{~s}$ till about $80 \mathrm{~s}$ ), and the third one (from about $80 \mathrm{~s}$ till about $300 \mathrm{~s}$ ). The last sublayer, which is deeper than $300 \mathrm{~s}$ of sputtering process, is a transition layer, in which all signals of electrolyte elements, that is, phosphorus, calcium, copper, oxygen, and nitrogen, are decreasing and the tantalum signal is the only increasing one up to the matrix level. A decreasing of oxygen and nitrogen may be found for depths related to sputtering times from $80 \mathrm{~s}$ till $300 \mathrm{~s}$ that should be recognized as a transition zone. However, it has to be noted that the derivatives of oxygen and nitrogen signals have the same inflection points, that is, about $125 \mathrm{~s}$, what may suggest that distribution of these elements in the sublayer takes place along two different curves; that is, that the sublayer may be divided into two additional parts, where the second one is thicker and less enriched in oxygen and nitrogen than the first one. Based on the oxygen and nitrogen GDOES signals and their derivatives, it can be stated that an additional sublayer boundary may be determined by the inflection points of these two curves. Similar information can be taken out from the copper and calcium signals and their derivatives. In case of copper, two regions are visible, that is, an enriched one, observed from the top to depth related to sputtering time that equals $150 \mathrm{~s}$, and a depleted zone for deeper layers. The calcium signal at the top sublayer was small and reached the 


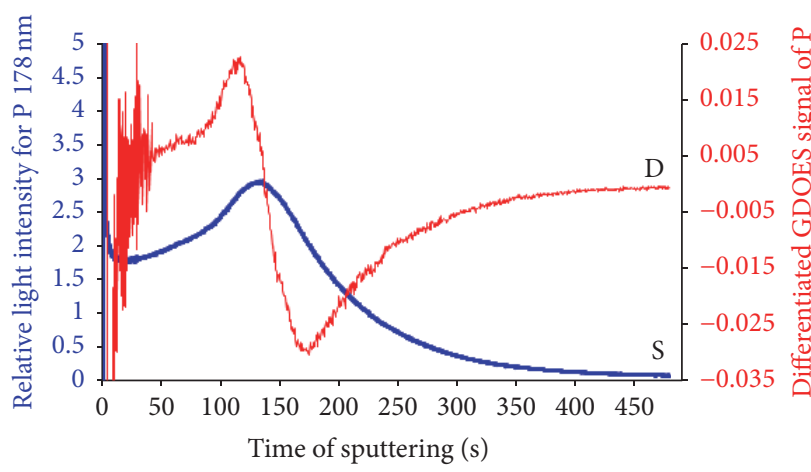

(a)

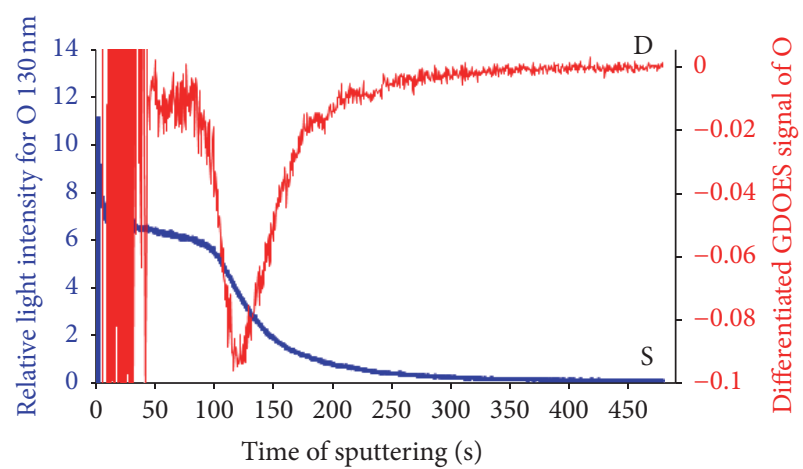

(c)

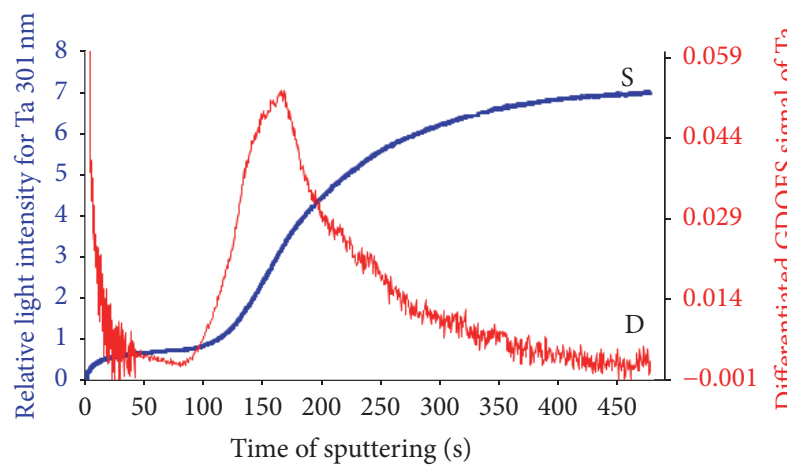

(e)

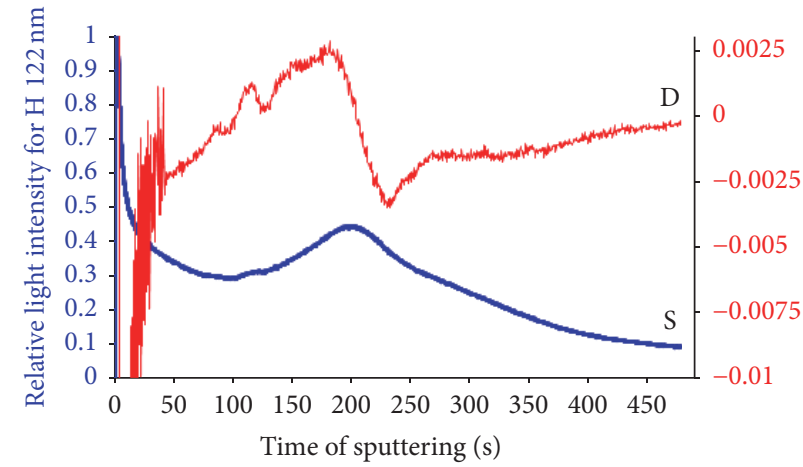

(g)

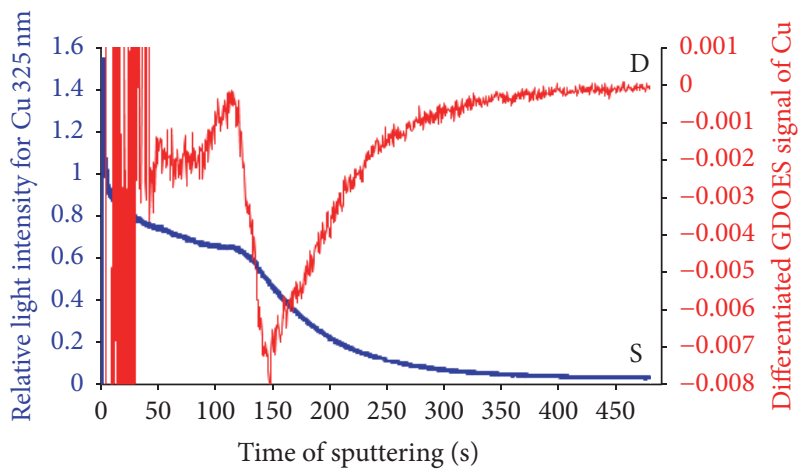

(b)

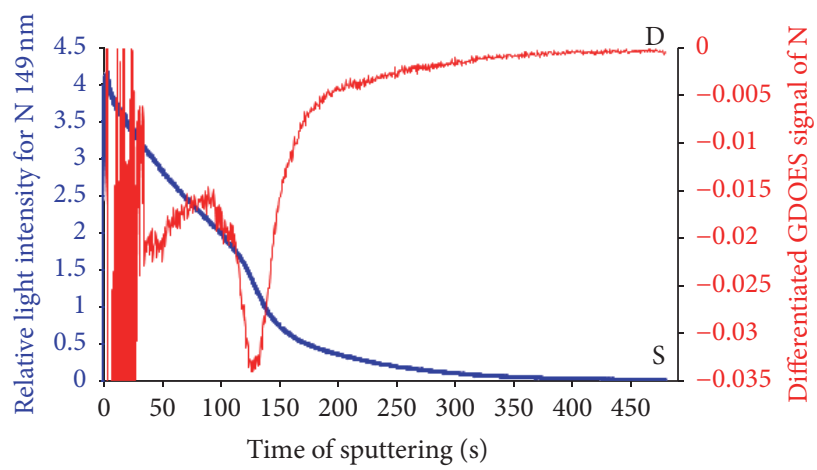

(d)

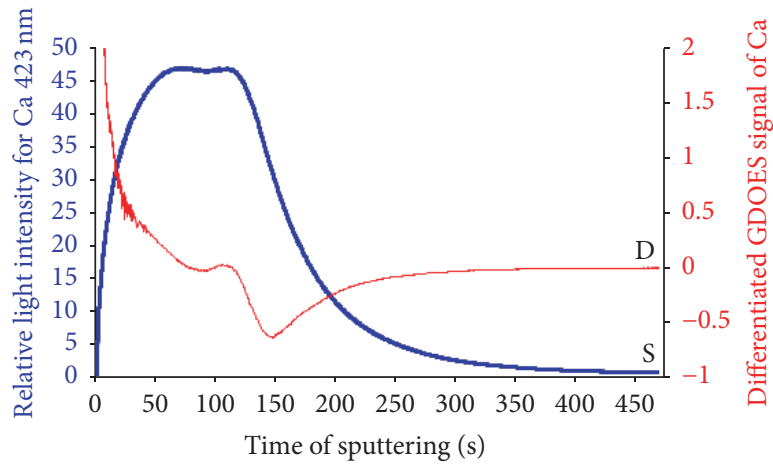

(f)

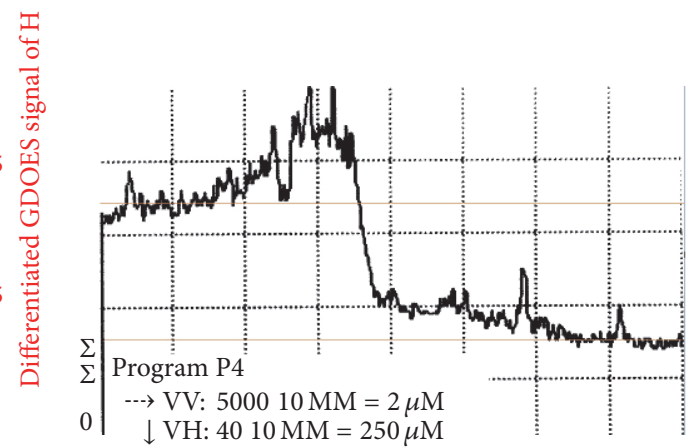

(h)

FIGURE 5: GDOES signals (S) of (a) phosphorus, (b) copper, (b) oxygen, (d) nitrogen, (e) tantalum, (f) calcium, and (g) hydrogen (blue lines) and their derivatives (D) (red lines) as well as (h) a GDOES crater's portion of coating formed on tantalum. (Cf. comment of Figure 3, smoothing with equaling spacing will allow "removing" the noise at the beginning.) 
maximum values in the second sublayer, that is, for sputtering times from $40 \mathrm{~s}$ till $150 \mathrm{~s}$. However, the inflection point of declining slopes of the curves has value of about $150 \mathrm{~s}$ and it is dividing the third sublayer into the two additional parts, that is, with and without copper and calcium enrichment. The part of PEO coating enriched in hydrogen can be found in the depth related to sputtering time in the range of $125-270 \mathrm{~s}$, which is confirmed by the analysis of derivative signal of hydrogen. Based on that analysis, additionally, the local maximum of differential of hydrogen signal for about $115 \mathrm{~s}$ may be found out: it corresponds to maximum of copper differential signal and maximum in differential signal of phosphorus.

Following the obtained GDOES results, it may be concluded that measured sputtering times related to depths of sublayers' boundaries are not only $40 \mathrm{~s}, 80 \mathrm{~s}$, and $300 \mathrm{~s}$, as it was found on the basis of Figure 4, but also $125 \mathrm{~s}, 150 \mathrm{~s}$, and $270 \mathrm{~s}$, what has been confirmed by the derivatives of the GDOES signals presented in Figure 5. The top layer, located in the sputtering time range of $0-40 \mathrm{~s}$, is containing the minimum amounts of tantalum and calcium and the highest amounts of phosphorus, copper, oxygen, nitrogen, and hydrogen. The second one, which is located in the sputtering time range of $40-80 \mathrm{~s}$, is semiporous and enriched in calcium, copper, and oxygen. The third one (80-300 s) consists of a local maxima of phosphorus as well as of hydrogen, what may be interpreted as molecules of water or phosphoric acid inside that sublayer. Moreover, that layer consists of four zones.

The fist zone appears to be for the sputtering time 80$125 \mathrm{~s}$, with the enrichment of calcium, copper, and oxygen signals and depletion of tantalum and hydrogen ones. In that zone, the increase of phosphorus and decrease of nitrogen signals are recorded. In the second zone (125-150 s), the maximum of phosphorus signal is noted as well as increase of tantalum and hydrogen signals and decrease of calcium, copper, oxygen, and nitrogen ones. In the next zone, that referred to the sputtering time between $150 \mathrm{~s}$ and $270 \mathrm{~s}$, a maximum of hydrogen signal was recorded. In addition, the signals of calcium, copper, phosphorus, oxygen, and nitrogen have a decreasing trend, while the tantalum one has got a growing trend. The last zone of the third sublayer, related to the sputtering time equaling $270-300 \mathrm{~s}$, includes an area in which all the signals have decreased, except that of tantalum.

\section{Conclusion}

Based on the XPS results, it has to be stated that PEO coating on Ta consists mainly of tantalum phosphate with some amount of calcium and/or copper phosphates. The tantalum $\left(\mathrm{Ta}^{5+}\right)$, calcium $\left(\mathrm{Ca}^{2+}\right)$, copper $\left(\mathrm{Cu}^{+}\right.$and $\left.\mathrm{Cu}^{2+}\right)$, and phosphorus $\left(\mathrm{PO}_{4}{ }^{3-}\right)$ were found out in the top layer of PEO coating. Hence, most likely the complex formulae contain tantalum, calcium, and copper phosphates, to describe the chemical compounds of the obtained PEO coating.

\section{Competing Interests}

The authors declare that there is no conflict of interests regarding the publication of this paper.

\section{Acknowledgments}

Messrs. Łukasz Dudek, Marcin Kułakowski, and Kornel Pietrzak, Ph.D. degree students of the Division of Bioengineering and Surface Electrochemistry, Department of Engineering and Informatics Systems, Koszalin University of Technology, Poland, are greatly acknowledged for their assistance in the experiments with getting the tantalum sample surface ready by Plasma Electrolytic Oxidation. Prof. Dr. Eng. Winfried Malorny from Hochschule Wismar, Germany, is thankful for providing access to the SEM apparatus allowing performing a part of the studies reported herewith.

\section{References}

[1] T. Espinoza, "Case study: tantalum in the world economy: history, uses and demand," POLINARES Consortium, Grant Agreement 224516, 2012.

[2] M. Sowa, A. Kazek-Kęsik, R. P. Socha, G. Dercz, J. Michalska, and W. Simka, "Modification of tantalum surface via plasma electrolytic oxidation in silicate solutions," Electrochimica Acta, vol. 114, pp. 627-636, 2013.

[3] C. C. Wang, F. Wang, and Y. Han, "The structure, bond strength and apatite-inducing ability of micro-arc oxidized tantalum and their response to annealing," Applied Surface Science, vol. 361, pp. 190-198, 2016.

[4] M. Petković, S. Stojadinović, R. Vasilić, I. Belča, B. Kasalica, and L. Zeković, "Plasma electrolytic oxidation of tantalum," Serbian Journal of Electrical Engineering, vol. 9, no. 1, pp. 81-94, 2012.

[5] M. Petković, S. Stojadinović, R. Vasilić, and L. Zeković, "Characterization of oxide coatings formed on tantalum by plasma electrolytic oxidation in 12-tungstosilicic acid," Applied Surface Science, vol. 257, no. 24, pp. 10590-10594, 2011.

[6] K. Rokosz and T. Hryniewicz, "Characteristics of porous biocompatible coatings obtained on Niobium and TitaniumNiobium-Zirconium (TNZ) alloy by Plasma Electrolytic Oxidation," Mechanik, vol. 12, pp. 15-18, 2015.

[7] A. Norlin, "Porous Niobium Oxide as Electrode Material and Manufacturing Process," US 20090292346 A1, 2005.

[8] A. Norlin, J. Pan, and C. Leygraf, "Fabrication of porous $\mathrm{Nb}_{2} \mathrm{O}_{5}$ by plasma electrolysis anodization and electrochemical characterization of the oxide," Journal of the Electrochemical Society, vol. 153, no. 7, pp. B225-B230, 2006.

[9] M. Sowa, A. Kazek-Kęsik, A. Krząkała et al., "Modification of niobium surfaces using plasma electrolytic oxidation in silicate solutions," Journal of Solid State Electrochemistry, vol. 18, no. 11, pp. 3129-3142, 2014.

[10] J. B. Bajat, V. Mišković-Stanković, R. Vasilić, and S. Stojadinović, "Corrosion evaluation of zirconium doped oxide coatings on aluminum formed by plasma electrolytic oxidation," Acta Chimica Slovenica, vol. 61, no. 2, pp. 308-315, 2014.

[11] Y. Chen, X. Nie, and D. O. Northwood, "Plasma electrolytic oxidation (PEO) coatings on a zirconium alloy for improved wear and corrosion resistance," in Proceedings of the Nuclear Frontiers 30th Annual Canadian Nuclear Society Conference and 33rd CNS/CNA Student Conference, p. 275, Canadian Nuclear Society, Alberta, Canada, 2009.

[12] W. Xue, Q. Zhu, Q. Jin, and M. Hua, "Characterization of ceramic coatings fabricated on zirconium alloy by plasma electrolytic oxidation in silicate electrolyte," Materials Chemistry and Physics, vol. 120, no. 2-3, pp. 656-660, 2010. 
[13] E. Matykina, R. Arrabal, P. Skeldon, G. E. Thompson, P. Wang, and P. Wood, "Plasma electrolytic oxidation of a zirconium alloy under AC conditions," Surface and Coatings Technology, vol. 204, no. 14, pp. 2142-2151, 2010.

[14] S. V. Gnedenkov, Y. P. Sharkeev, S. L. Sinebryukhov et al., "Functional coatings formed on the titanium and magnesium alloys as implant materials by plasma electrolytic oxidation technology: fundamental principles and synthesis conditions," Corrosion Reviews, vol. 34, no. 1-2, pp. 65-83, 2016.

[15] Y. Han, S.-H. Hong, and K. Xu, "Synthesis of nanocrystalline titania films by micro-arc oxidation," Materials Letters, vol. 56, no. 5, pp. 744-747, 2002.

[16] T. H. Teh, A. Berkani, S. Mato et al., "Initial stages of plasma electrolytic oxidation of titanium," Corrosion Science, vol. 45, no. 12, pp. 2757-2768, 2003.

[17] C. Fei, Z. Hai, C. Chen, and X. Yangjian, "Study on the tribological performance of ceramic coatings on titanium alloy surfaces obtained through microarc oxidation," Progress in Organic Coatings, vol. 64, no. 2-3, pp. 264-267, 2009.

[18] K. Rokosz, T. Hryniewicz, and S. Raaen, "Development of plasma electrolytic oxidation for improved Ti6Al4V biomaterial surface properties," The International Journal of Advanced Manufacturing Technology, vol. 85, pp. 2425-2437, 2015.

[19] K. Rokosz, T. Hryniewicz, S. Raaen, and P. Chapon, "Investigation of porous coatings obtained on $\mathrm{Ti}-\mathrm{Nb}-\mathrm{Zr}$-Sn alloy biomaterial by plasma electrolytic oxidation: characterisation and modelling," The International Journal of Advanced Manufacturing Technology, vol. 87, no. 9, pp. 3497-3512, 2016.

[20] W. Simka, A. Iwaniak, G. Nawrat et al., "Modification of titanium oxide layer by calcium and phosphorus," Electrochimica Acta, vol. 54, no. 27, pp. 6983-6988, 2009.

[21] K. Rokosz, T. Hryniewicz, Ł. Dudek, D. Matýsek, J. Valíček, and M. Harničárová, "SEM and EDS analysis of surface layer formed on titanium after plasma electrolytic oxidation in $\mathrm{H}_{3} \mathrm{PO}_{4}$ with the addition of $\mathrm{Cu}\left(\mathrm{NO}_{3}\right)_{2}$," Journal of Nanoscience and Nanotechnology, vol. 16, no. 8, pp. 7814-7817, 2016.

[22] Z. Yao, Y. Jiang, F. Jia, Z. Jiang, and F. Wang, "Growth characteristics of plasma electrolytic oxidation ceramic coatings on Ti-6Al-4V alloy," Applied Surface Science, vol. 254, no. 13, pp. 4084-4091, 2008.

[23] R. O. Hussein, X. Nie, and D. O. Northwood, "A spectroscopic and microstructural study of oxide coatings produced on a Ti-6Al-4V alloy by plasma electrolytic oxidation," Materials Chemistry and Physics, vol. 134, no. 1, pp. 484-492, 2012.

[24] A. Krząkala, J. Młyński, G. Dercz et al., "Modification of Ti 6Al$4 \mathrm{~V}$ alloy surface by EPD-PEO process in $\mathrm{ZrSiO} 4$ suspension," Archives of Metallurgy and Materials, vol. 59, no. 1, pp. 199-204, 2014.

[25] X. Zhang, X. Huang, Y. Ma, N. Lin, A. Fan, and B. Tang, "Bactericidal behavior of $\mathrm{Cu}$-containing stainless steel surfaces," Applied Surface Science, vol. 258, no. 24, pp. 10058-10063, 2012.

[26] Casa Software Ltd, CasaXPS: Processing Software for XPS, AES, SIMS and More, 2009, http://www.casaxps.com.

[27] X. Yao, X. Zhang, H. Wu, L. Tian, Y. Ma, and B. Tang, "Microstructure and antibacterial properties of $\mathrm{Cu}$-doped $\mathrm{TiO}_{2}$ coating on titanium by micro-arc oxidation," Applied Surface Science, vol. 292, pp. 944-947, 2014.

[28] C. D. Wagner, A. V. Naumkin, A. Kraut-Vass, J. W. Allison, C. J. Powell, and J. R. Rumble Jr., NIST Standard Reference Database 20, Version 3.4, 2003, http://srdata.nist.gov/xps.
[29] F. Hempel, B. Finke, C. Zietz, R. Bader, K.-D. Weltmann, and M. Polak, "Antimicrobial surface modification of titanium substrates by means of plasma immersion ion implantation and deposition of copper," Surface and Coatings Technology, vol. 256, pp. 52-58, 2014.

[30] J. Morales, J. P. Espinos, A. Caballero, and A. R. GonzalezElipe, "XPS study of interface and ligand effects in supported $\mathrm{Cu}_{2} \mathrm{O}$ and $\mathrm{CuO}$ nanometric particles," The Journal of Physical Chemistry B, vol. 109, no. 16, pp. 7758-7765, 2005.

[31] W. Zhu, Z. Zhang, B. Gu, J. Sun, and L. Zhu, "Biological activity and antibacterial property of nano-structured $\mathrm{TiO}_{2}$ coating incorporated with Cu prepared by micro-arc oxidation," Journal of Materials Science \& Technology, vol. 29, no. 3, pp. 237-244, 2013.

[32] A. J. Marenco, D. B. Pedersen, and S. Trudel, "Inducing ferromagnetic behavior in $\mathrm{Cu}$ nanoparticles and thin films through nonstoichiometric oxidation," The Journal of Physical Chemistry C, vol. 120, no. 13, pp. 7388-7396, 2016.

[33] A. Yin, X. Guo, W.-L. Dai, and K. Fan, “The nature of active copper species in $\mathrm{Cu}-\mathrm{HMS}$ catalyst for hydrogenation of dimethyl oxalate to ethylene glycol: new insights on the synergetic effect between $\mathrm{Cu}^{0}$ and $\mathrm{Cu}^{+}$," The Journal of Physical Chemistry $C$, vol. 113, no. 25, pp. 11003-11013, 2009.

[34] Pulsed RF Glow Discharge Optical Emission SpectrometryUltra Fast Elemental Depth Profiling, HORIBA Scientific, Printed in France-CHORIBA Jobin Yvon: 7 pages, 2014, http://www.horiba.com/scientific/products/atomic-emissionspectroscopy/glow-discharge/.

[35] J. Kolmas, E. Groszyk, and D. Kwiatkowska-Rózycka, "Substituted hydroxyapatites with antibacterial properties," BioMed Research International, vol. 2014, Article ID 178123, 15 pages, 2014. 

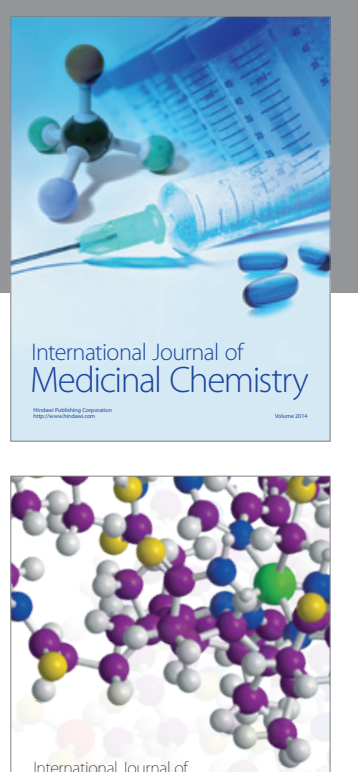

Carbohydrate Chemistry

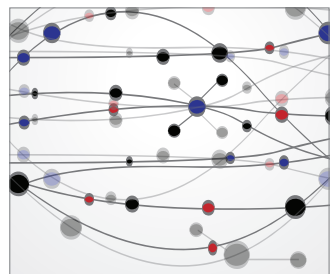

The Scientific World Journal
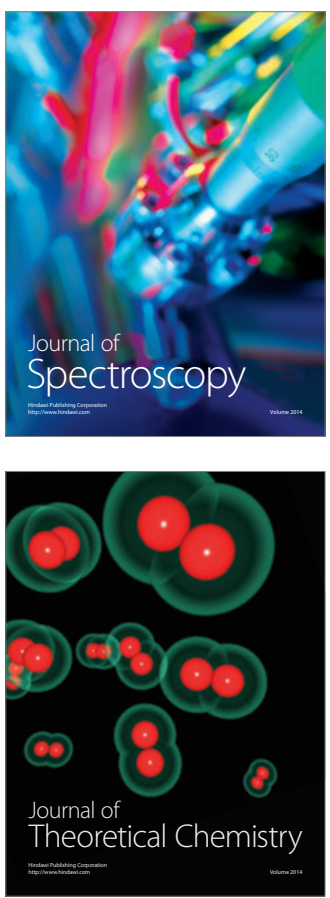
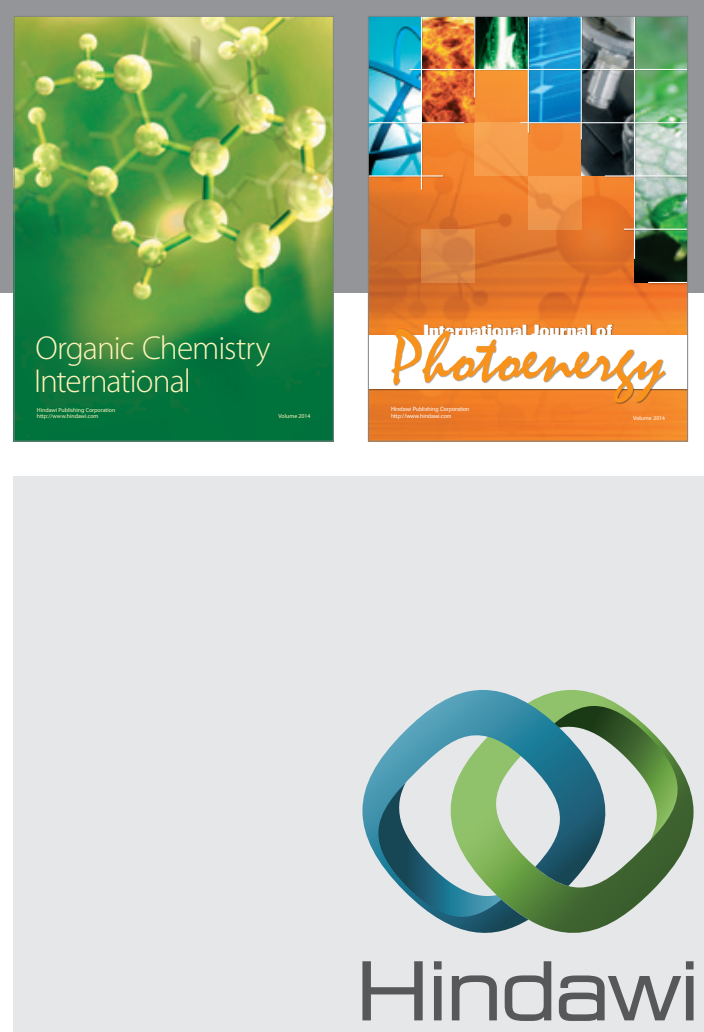

Submit your manuscripts at

http://www.hindawi.com

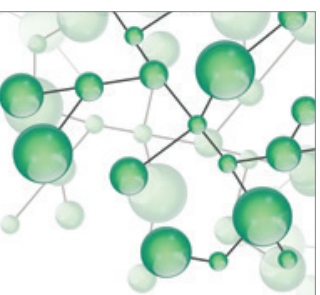

International Journal of

Inorganic Chemistry

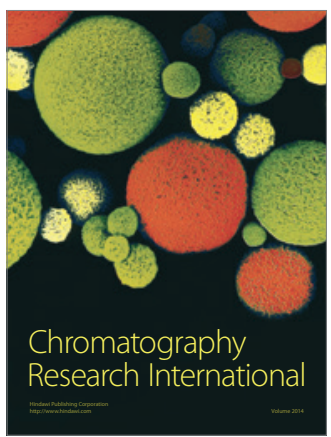

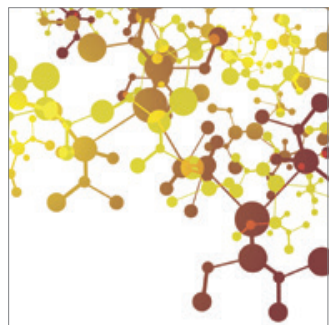

Applied Chemistry
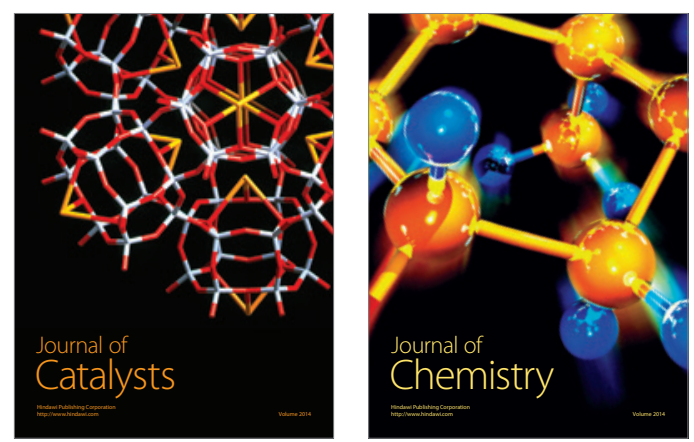
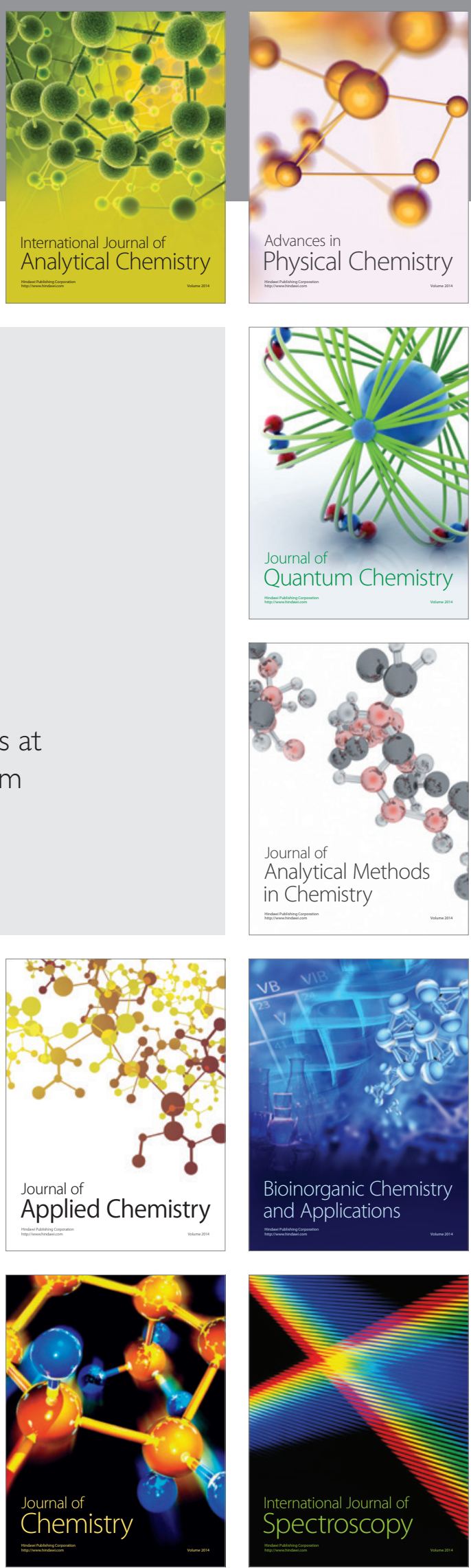